\title{
All that glitters is not gold: The shaping of contemporary journal peer review at scientific and medical journals
}

\author{
Joanne Gaudet ${ }^{1}$ \\ ${ }^{1}$ Department of Sociology, University of Ottawa, Ottawa ON K1N 6N5
}

\begin{abstract}
AUTHOR'S NOTE: This sociological preprint is one of a series in which I explore ignorance (re)production in journal peer review and journal peer review dynamics more generally. The main target audience is natural science and medical researchers, publishers, and policymakers and a secondary audience is social scientists with an interest in peer review at natural scientific and medical journals.
\end{abstract}

(C) 2014 The author (Joanne Gaudet). For any use, the original work must be properly cited: Gaudet, J. 2014. All that glitters is not gold: The shaping of contemporary journal peer review at scientific and medical journals. uO Research. Pp. 1-23. http://hdl.handle.net/10393/31238

\begin{abstract}
The main goal for this paper is to propose an analysis of the shaping of contemporary journal peer review at natural science and medical journals. I investigate journal peer review beyond a pre-constructed process or self-evident object of study based on common experience. To do so, I use the theoretical concept of social form to capture how individuals relate around a particular content. For the social form of 'boundary judgement' (i.e., journal peer review), content refers to decisions from the judgement of scientific written texts held to account to an overarching knowledge system. I shun journal peer review as a supposedly purely rational process borne of a need for rationality - instead, I explore the social conditions, dynamics, processes, and contexts that contributed to its contemporary shaping. Analysis highlights how economic dynamics play a critical role in shaping pre-publication journal peer review (traditional peer review) as a paradigmatic form of peer review to the detriment of more open journal peer review forms and of journal business models that stray from the traditional reader-pay model. I conclude that all that glitters is not gold with traditional peer review.
\end{abstract}

\section{Introduction}

The main goal for this paper is to propose an analysis of the shaping of contemporary journal peer review at natural science and medical journals. I focus more particularly on the shaping of the paradigmatic form of pre-publication journal peer review (traditional peer review). By paradigmatic, I mean that traditional peer review acts as the prototype for journal peer review against which other forms are typically compared (Gaudet, 2014a:14; related in Flyvbjerg, 2006:230,202; 2001:80-81; Bourdieu et al., 1968:79-80).

The paper draws from, and contributes to, scholarship in library sciences on journal publication (i.e., Guédon, 2001; Pöschl, 2010) and on journal peer review more generally (i.e., Zuckerman and Merton, 1971; Young et al., 2008; Hirschauer, 2010). The paper also complements work on the historical shaping of journal peer review (Gaudet, 2014b; Gould, 2012, 2013) by focusing on contemporary shaping starting roughly at the end of the twentieth century through to the early teens of the twenty-first century.

To start, natural scientists (and some social scientists) investigating journal peer review frequently frame it as a supposedly purely rational process borne of a need for 
rational decision-making (Hirschauer, 2010:73; Biagioli, 2002:13). In espousing such a rational theory for journal peer review, researchers implicitly take the object as selfevident and as having started at the first journals in 1665 without tending to its shaping (i.e., Bornmann et al., 2010; Campanario, 2009; Godlee, 2002; see history in Johns 1998, 2000). This assumes journal peer review as disembodied from the social conditions, the dynamics, the processes, and the contexts that contributed to its historical shaping (Gaudet, 2014b; Gould, 2013) and that contribute to its contemporary shaping.

Furthermore, when researchers focus solely on the object of study itself - such as social scientists (i.e., Jasanoff (1990:62) and Latour and Woolgar (1986:121)) and natural scientists (i.e., Bornmann, 2010; Ioannidis et al., 2011) - this leaves invisible how journal peer review is shaped and reshaped (related in Lopez, 2009:29-30). Jasanoff (1990), for example, proposed that "...peer review is simply part of the process of construction by which scientists certify some claims and conventions as valid" (1990:62). Jasanoff's (1990) understanding corresponds to a sociologically informed function for peer review: the certification of the validity of claims and conventions.

In keeping with Durkheim ([1894]1988), however, I advance that to understand an object of study sociologically is not only to study what role it plays or its function (Durkheim [1894]1988:182-184). This would limit analysis to answering the question 'what for' as proposed by Jasanoff (1990) above. For Durkheim, determining an object of study's function does not equate with proposing an explanation of “....comment [l'object] est né ni comment il est ce qu'il est"1 ([1894]1988:183). From a sociological perspective, investigating the shaping of an object of study helps avoid reifying a pre-constructed object. Traditional peer review might appear 'natural' when compared with alternative social forms of journal peer review that might appear 'unnatural'. Such framings, however, can owe to relations of power that render traditional peer review 'natural' and invisible (see Lips, 1991). Furthermore, Bourdieu et al. (1968) advanced that research into shaping should consider the use of a paradigmatic case in comparative perspective (1968:79-80).

To reach the main goal of this paper, therefore, I investigate how journal peer review, and specifically the paradigmatic form of traditional peer review, is what it is at contemporary scientific and medical journals. Focusing on relations as fundamental entities that construct the object (Durkheim, [1894]1988:195), I look to the relational development of the object in context - historically and spatially ([1894]1988:227). For example, in his critical study of bioethics, Lopez (2004) drew on Durkheim to argue that sociologists "... should reflect on the wider social and historical conditions of the emergence of ethics as an object" (2004:891) beyond discourse. Finally, broader historical analysis of the shaping of journal peer review (Gaudet, 2014b) has already contributed to refining the function Jasanoff proposes for journal peer review with the use of the concept of social forms.

Using the theoretical concept of social forms provides an established conceptual tool to capture the shaping of journal peer review. This work focuses mainly on the proposed social form of 'boundary judgement' where individuals aggregate around a common content - decisions as to what can be deemed scientific (or not) - based on the

\footnotetext{
${ }^{1}$ My translation "... how an [object] is born and neither how it is what it is".
} 
judgement of scientific written texts against an overarching knowledge system (Gaudet, 2014a; Gaudet, 2014b). Social form understanding refines Jasanoff's proposed function.

Furthermore, the main social form, boundary judgement, interacts with a second social form, scientific exchange (latter in Levine, 1971:43-44) (cf., the communication of scientific knowledge). For example, a scientist who presents a paper at a conference or submits a paper for publication in a journal is an actor engaging in the form of scientific exchange. An example of interaction between the two forms is when a boundary judgement form such as traditional peer review makes valuable exchange possible only if it is contingent on the boundary judgement.

Investigating social forms means to "...identify and classify the different forms of social interaction; [...] to study the conditions under which they emerge, develop, flourish, and dissolve; and to investigate their structural properties"(Levine, 1971:xxviixxviii; related in Donati, 2011:90-91). The approach I take builds on Hirschauer (2010) who constructed journal peer review as reciprocal accountability for authors and editorial readers. Structural properties refer to elements that shape relations in a social form (i.e., types of relations such as economic, power, political, accountability relations, and structural dynamics such as anonymity, temporality of review, secrecy of review, and actors). In traditional peer review there are multiple and potentially intersecting relations of accountability and relations (Gaudet, 2014a). An example of a structural property is closed access to editorial judgements in traditional peer review that shields these from outside actors while they are being constructed through negotiations among authors, referees, and editors and regulates closed access following a decision for a manuscript. I couple social form understanding with existing scholarship on shaping.

In existing scholarship on journal peer review, Hirschauer (2010) and to a lesser extent Biagioli (2002) at least partially engaged with the social conditions, the dynamics, the processes, and the contexts that have helped shape contemporary journal peer review. Their respective investigations of these dynamics left many questions unanswered, however, especially concerning the economics of publishing as well as the roles of libraries and indexes.

Guédon (2001) partially tended to these economic and institutional gaps by exploring the shaping of scientific journals. His analysis included the start of scientific journals, economic conditions surrounding scientific communication and their impact on libraries, consequence of the launch of the Science Citation Index in commercial scientific publishing, and changes arising from networking and digitization in scientific communication. Where Guédon's (2001) work also generated more questions, nonetheless, is specifically for details on journal peer review in these dynamics. This paper thus builds on Hirschauer (2010), Biagioli (2002), and Guédon (2001) by focusing on contemporary shaping for journal peer review.

The paper unfolds in three sections. First, I explore the intersection of scientific exchange and economic dynamics in journal publishing. Second, I turn the focus on the reshaping of a structural property in traditional peer review, referee anonymity. I examine two extremes: from removing anonymity to instilling double-blind peer-review. Lastly, I tend to the rise of the Web and of new forms of boundary judgement. The section delves into two related open access dynamics: funding agency mandated knowledge mobilization for publicly funded research and Web-based scientific exchange such as those at preprint servers. 


\section{Section I - The intersection of scientific exchange and economic dynamics}

First, I explore the intersection of scientific exchange and economic dynamics in shaping journal peer review. It is important to recall that it was only in the nineteenth century that scientists constructed periodicals as a "...proper place for publishing new work, though still considered as preparatory for treaties in book form" (Lefanu, 1984:vii). Then in the early twentieth century, periodicals rose above books as the privileged medium of scientific exchange (see physics in Bazerman, 1988:158; more generally in Gross and Harmon, 2014:5; Philosophical Transactions in Bryce et al., 1994:292; Lefanu, 1984:viii). The dominance of journals no doubt helped reproduce relations of power journal publishers and editors forged over manuscripts through journal peer review, over the content of exchange (in the form of copyrights), and over authors (cf., devaluing author-led publishing options). Dominance further shaped journal peer review as a main valuation mechanism for the content of scientific exchange.

Although journal peer review dominated valuation, there was (and still is) heterogeneity in social forms at journals. In the early twentieth century, for example, some German physics journals did not appear to use referees and detailed anonymous referee judgements in contrast to American and British physics journals at the time (Kennefick, 2005). Medical journals such as The Lancet were also known not to have always made use of referees up until the 1970s (Burnham, 1990:1326; Ingelfinger, 1974:692). In addition, journal publishers can manage multiple concurrent social forms of journal peer review (cf., Nature Publishing Group and The Lancet). These can range from traditional peer review with closed access to original manuscripts and editorial documents and anonymous referees to public space peer review with open access to original manuscripts and editorial documents and non-anonymous referees with potential for infinite review (see comparison in Gaudet, 2014a). In the caption for Figure 1, I outline main structural properties for the paradigmatic form of traditional peer review. Depending on the actor, other relations include those with editorial guidelines, sponsors/funders, empiricism, board members, advertisers, the journal publishers/owners, judgements, the boundary judgement decision, and readers (Gaudet, 2014a; 2014b).

The section develops in five sub-parts. First, I briefly explore dominant journal publishers before the full deployment of Eugene Garfield's Science Citation Index (SCI) (Garfield and Sher, 1963) and the subsequent construction of 'core journals' (Garfield, 1970). I use the SCI as a significant marker for change in dominant journal publishers from mostly not-for-profit publishers to a rise in for-profit commercial publishers, in keeping with Guédon's (2001) analysis.

\section{1 - Dominant journal publishers before the Science Citation Index (SCI)}

Although periodicals were a privileged medium from the twentieth century onward, they did not readily lead to profitability. This meant that learned societies and university presses dominated journal publication with mostly not-for-profit goals. Even after World War II, there were few commercial publishers in scholarly journal publishing as it was deemed a 'secondary business field' (2001:23). 
Figure 1: Model of the boundary judgement social form of traditional peer review at natural science and medical journals (Gaudet, 2014b:7)

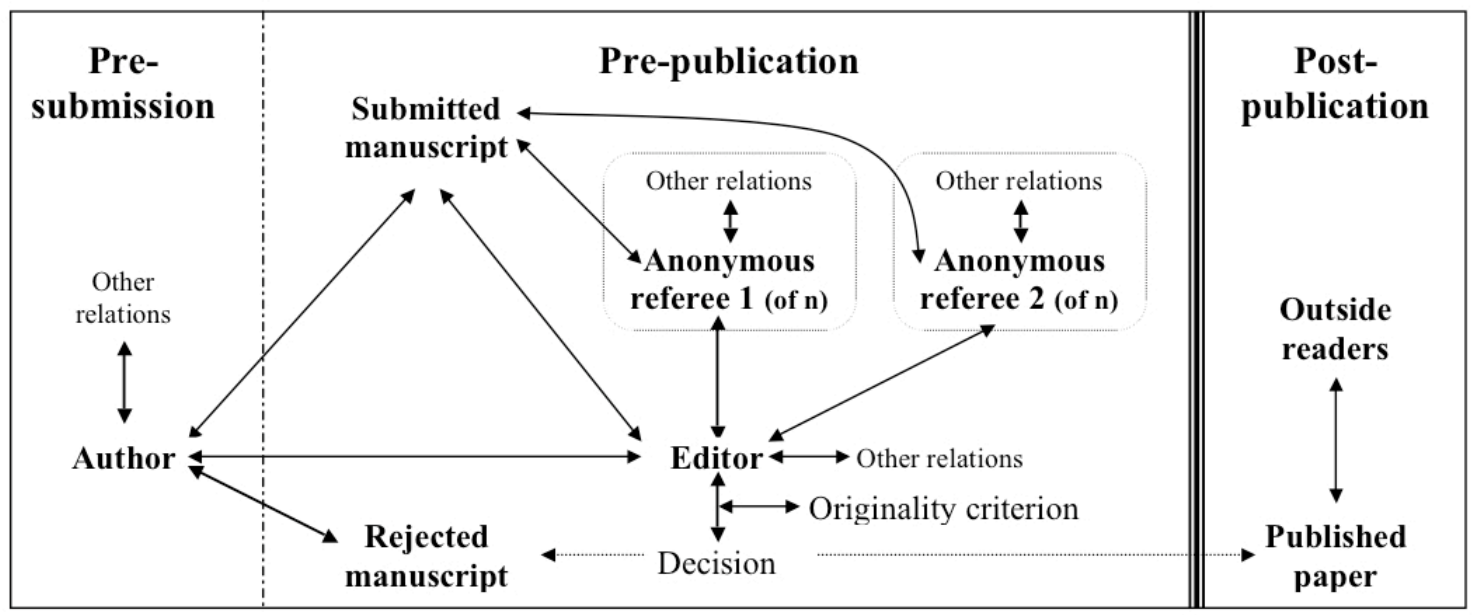

Structural properties start with 3 temporal periods from left to right: pre-submission, pre-, and post-publication. Main actor roles depicted are author, submitted manuscript, editor, anonymous referees ( 1 and 2 of $n$ ), and in the post-publication period, outside readers. Each actor role holds relations as depicted with arrows and additional respective social relations and relations of accountability as 'Other relations'. The editor role uses a criterion of originality to construct a decision. The boundary judgement decision relates with the editor and either a rejected manuscript or a published paper. Scientific exchange contingent on review is designated with bold vertical lines between pre- and post-publication that also depicts pre-publication as structurally closed to outside actors.

I advance that the content of scientific exchange at not-for-profit publishers mostly retained (and retains) a meaning of 'scientific' or 'epistemic' value to the content of scientific exchange (cf., scientific knowledge and ignorance ${ }^{2}$ ) following journal peer review. Value is constructed in journal peer review with accountability to the learned society $^{3}$ or university, with a goal to foster further scientific research practices and exchange (Gaudet, 2014a; related in Parrott, 2004; Kennefick, 2005). Such value can be set in contrast with 'newsworthy' or 'news' value to which I return below.

To understand economic dynamics, however, requires looking at core economic elements. In the section's second sub-part therefore, I explore core economic dynamics for journals including free content and review provided by academics, revenue for journal publishers, and prestige and priority for authors.

2 - Economic-related dynamics: 'free' content of scientific exchange, revenue for journal publishers, and prestige and priority for authors

In boundary judgement social forms that relate authors, referees, and journal publishers (cf., not-for-profit publishers and commercial publishers), authors give the content of scientific exchange free of charge, referees give their time and expertise to engage in judgement, and journal publishers generate revenue and retain copyrights for the content (see Johns, 1998; Guédon, 2001:8-9; see open access and changes to

\footnotetext{
${ }^{2}$ Ignorance is non-pejorative as the limits and borders of knowing in science (Gross, 2010; Gaudet, 2013).

3 I use 'learned society' although contemporary academic associations (or variations thereof) are sometimes referred to as 'scholarly societies' or 'professional associations'.
} 
copyright below). In a context dominated by not-for-profit publishers, free content of exchange and free referee role services do not appear to have stirred controversy.

For authors furthermore, then and still today, publications help gain prestige and if a paper presents 'novel' knowledge, helps ensure priority for the author (Zuckerman and Merton, 1971). Author prestige is intrinsically linked with journal prestige (Guédon, 2001:21; branding role of journals in Young et al., 2008). As peer reviewed publications count towards promotions and prizes (Zuckerman and Merton, 1971; Young et al., 2008), journal peer review therefore retains a central and important role in academic professional and economic success (cf., funding) (Musselin, 2013). In turn, this helps reproduce journal peer review as a valuation mechanism for the content of exchange.

A second meaning for the content of exchange contingent on journal peer review grew more prominent in the late 1960s: content of scientific exchange as news. In the third sub-part, I tend to the Ingelfinger rule.

\section{3 - The Ingelfinger rule}

In the late 1960s, then editor of the New England Journal of Medicine "...Franz Ingelfinger $[. .$.$] learned that two publications that were mailed free to doctors had$ reported details of a paper before its publication in his subscription-based, peer-reviewed journal. Ingelfinger believed that the earlier reports "demolished" their newsworthiness, which he viewed as a major element of the commercial profitability of his journal" (Altman, 1996:1382). At that point, he developed a policy - known as the Ingelfinger rule - whereby his journal would reject papers that had been previously published elsewhere. Other journals followed suit (Altman, 1996).

Of importance in this work is that the rule explicitly constructed the content of scientific exchange with a 'news' meaning. In addition, the rule explicitly constructed peer review as a dominant mechanism to valuate knowledge and ignorance. Moreover, at commercial publisher and not-for-profit publishers, the editor holds a relation to economic goals in the social forms of boundary judgement used. At for-profit journals, however, this relation includes a goal of maximizing profit by making exchange entirely contingent on journal peer review as is evident with the rule.

The rule thus decreases potential exchange of knowledge and ignorance outside of a merchant relation by reducing access to one source - the original journal accessible through reader-pay dynamics. This contrasts with then first editor Henry Oldenberg at Philosophical Transactions in the $17^{\text {th }}$ century who would send papers to other journals in order to secure priority for authors with a wider audience (McClellan, 1985:310). Contemporary open access dynamics, discussed below, appear to somewhat curtail the Ingelfinger rule. In keeping with rising commercial interest in scientific journals, in the fourth sub-part I explore the launch of the SCI and the Impact Factor measurement tool.

\section{4 - The launch of the SCI and the Impact Factor}

Early in the 1960s, Eugene Garfield developed the SCI. Citation indexes are essentially "...ordered lists of references which are accompanied by citations for documents in which they have been cited" (Garfield and Sher, 1963:105). With the SCI, came the construction of an apparent 'hard core' (Garfield, 1970:670) or 'scientific core' 
(Guédon, 2001:20) of essential scientific literature. In practice, however, the apparent 'core' only represented a fraction (and still does) of scientific journals published worldwide (2001:20).

In the decades that followed, commercial publishers seemed to notice 'core journals' while registration to university studies increased considerably and the number of libraries also increased in the United States and worldwide (2001:23). In essence, core journals were constructed as vital for library collections, which in turn created conditions for an inelastic market. In an inelastic market, pricing has little impact on demand, and demand has little impact on pricing (2001:23). Libraries, for example, typically subscribe to core journals such as Science and Nature regardless of price.

On the one hand, not-for-profit publishers were not very likely to exploit an inelastic market given that the goal is not profit. Commercial for-profit publishers ${ }^{4}$, on the other hand, appear to have steadily gained ownership from not-for-profit publishers during the 1970s through to the early 1980s and increasingly dominated the core market, changed subscription models, and purportedly increased prices (2001:24; in physics, Barschall, 1986; American Mathematical Society (AMS), 2011; in ecology, Bergstrom and Bergstrom, 2006; Parrott, 2004).

Furthermore, attempts to compare costs between not-for-profit and for-profit commercial publishers and to highlight potential arbitrariness in higher pricing in physics and mathematics were met with shows of force. At least one publisher sued in several countries, and threatened suits, against those comparing costs (Stanford University, 1997; Garfield, 1998; Sent and Klamer, 2002:266-267). Other publishers engaged in hostile takeovers or alienated editorial boards with ever-rising journal costs prompting academics involved to resign and launch their own, lower-priced journals (Sent and Klamer, 2002:267-268). Economists Sent and Klamer (2002) argued that the dominance of commercial publishers with a goal to make profit were "...efforts to commodify knowledge" (2002:269). Knowledge as a commodity here reaches outside of the realm of epistemic value and academic career management. In a recent example in the Fall of 2013, a debate on economics of scientific publishing (mostly at scientific and medical journals) was delayed for over six months as journal editors refused to "...excise the major part of the [debate] Proposition paper" (Macdonald, 2013:168) - rendering visible editors' relation of accountability to journal owners/publishers.

To contextualize the economics, in 2008 the Research Information Network estimated at 25 billion Euros the global cost of publishing, distributing, and accessing articles (Cambridge Economic Policy Associates, 2008:13). The global cost included an estimated 1.9 billion Euros non-cash costs for peer review services offered by academics. A large part of these costs appear to be borne by academic institutions, some estimated $53 \%$ through library subscriptions, and $23 \%$ as unpaid costs for peer review performed by academic institution members. To give examples of purported profit, in 2011 The Economist pegged Dutch publisher Elsevier's profit margin at 38\% on 3.2 billion US dollars of revenue and German publisher Springer's margin at 36\% on $\$ 1.1$ billion US dollars worth of sales (Editorial Staff, 2013a:79). Profit numbers must be understood as highly volatile, according to Stevenson (2013), however, where profit margins can easily

\footnotetext{
${ }^{4}$ There are variations on for-profit and not-for-profit. For example, some journals are jointly owned by a for-profit commercial publisher and a not-for-profit learned society whereas others are owned by a not-forprofit learned society but the society engages a for-profit publisher to manage publishing and subscriptions.
} 
decrease (2013:266). Stevenson (2013) also contextualized not-for-profit academic society revenue as critical to their operations and to societies' very survival, sometimes resulting in higher journal prices (2013:266-267).

I advance that increased power relations in the 'core journals' market by commercial publishers with a seeming goal of constructing the content of scientific exchange as exclusive news increases naturalization (Lips, 1991) of traditional editorial peer review. Naturalization has also spread outside of science where the general public and news reporters, for example, hold traditional peer review in high esteem as indicative of good science (Smith, 2006:178; Biagioli, 2002:34-35) ${ }^{5}$. Not-for-profit science advocacy organizations such as 'Sense About Science', for example, advance that "[b]ecause it indicates that research has been scrutinized by independent experts in the field, peer review is also an important consideration for policy makers, reporters and the public when weighing up research claims and debates about science" (Sense About Science, 2012). The apparent rigour of traditional peer review purportedly contributes to the quality of the content of scientific exchange, which in turn contributes to branding individual journals, researchers, and papers as prestigious. Journals that can bestow prestige on authors and on the papers that they publish can thus help shape scholarly careers (Young et al., 2008; Guédon, 2001:21). On the topics of branding and careers, I turn to the impact factor.

\section{Impact factor}

Not long after the launch of the SCI, the impact factor measure was constructed (2001:21) to rate journals in the SCI. Impact factor is a relative measure of citations (total number of citations for a period of time divided by published items (i.e., articles, reviews, and proceedings papers)) for a given journal. A journal with a higher number of citations per published item would yield a higher impact factor than a journal with a lower number of citations for the same number of published items, for example. The measurement did not take account of potentially varying citation practices in areas of study or disciplines, it simply homogenized all journals and constructed a purported 'impact factor' (2001:21).

Guédon (2001) argued that the impact factor has allowed commercial publishers to brand journals (cf., a high impact journal as more prestigious) and render invisible the individual articles (and I add the content of exchange) that make up a journal. This then allowed commercial publishers, Guédon (2001) further argued, to engage in "...their financially lucrative technique of branding individual scientists" (2001:21). Thus, high ranking scientists must attempt to publish in these journals to "... seek visibility, prestige, authority (and improved institutional ranking)" (2001:21), which seemingly further constructs the importance of the individual journals, and not the content of exchange.

Shielding scientific exchange from public gaze

Related with the virtuous circle of prestige, I advance, is a need for dominant journals ${ }^{6}$ and those who uphold a need for prestige to advocate the merits of traditional

\footnotetext{
${ }^{5}$ See recent writings outside of science on perceived limitations of peer review and academic boycotts of commercial publishers in The Economist magazine (Editorial Staff, 2013b; Editorial Staff, 2012).

${ }^{6}$ It is important to note that publishers managing dominant (flagship) journals typically manage more than
} 
peer review as a tool to ensure scientific quality. In addition, perhaps an appealing aspect of traditional peer review in the construction of 'news' might be structural secrecy that effectively shields original manuscripts and editorial judgements and decisions, including rejections, from the pubic gaze (see Figure 1; Gaudet, 2014a:8-10) and shifts the focus on a narrow selection of published papers branded as prestigious scientific news.

A co-founder of the Public Library of Science, Eisen, offered that "... [a]t best, even when people are carrying out peer review in an honest and sincere way, it represents the view of a couple of scientists at a single fixed point in time. And very, very often, those scientists miss clear flaws in the work, they miss poor design in the experiment" ( $\underline{\mathrm{CBC}, 2013}$ ). The manner in which Eisen framed journal peer review is one where referees are engaged in a localized role, and that secrecy for original manuscripts and editorial judgements effectively prevent thorough and long-term peer review under a public gaze (see Gaudet, 2014a; 2014b).

In contrast, open access to original manuscripts and editorial judgements and decisions render conflicting and unruly epistemic dynamics and arguments and counterarguments visible (see public space peer review in Gaudet, 2014a:10-12). Such details might appear 'messy' and are not conducive to constructing scientific knowledge as absolute and as newsworthy. In keeping with this understanding, Eisen advanced that post-publication peer review should continue for the 'lifetime' of a paper (CBC, 2013). Public space peer review, as I have argued elsewhere holds relational potential for longterm self-correction dynamics in science (Gaudet, 2014a:12).

Moreover, shielding referee identities from the public eye can reify traditional peer review as based on supposedly absolute scientific knowledge. Embedded in anonymous relations is an assumption that who holds the role of referee does not matter. Such absolute knowledge harks back to a shift of authority from religious Divine Right to scientific understanding of Nature that suppressed other ways of knowing (Zavarzadeh and Morton, 1991:68; see heterogeneous ways of knowing in Laplante, 2014). Absolute confidence in anonymous judgements that is asked of scientists and a wider audience appears to mimic those of 'faith' as a specific type of confidence where "[ $t]$ his condition of faith, in a perfectly pure form, detached from every sort of empirical consideration, probably occurs only within the sphere of religion" (Simmel, 1906:450). I argue here that Simmel could not have anticipated the type of faith that the sphere of science constructed with the use of anonymous referees.

Replacing absolute confidence in religion with absolute confidence in science is thus another way of understanding traditional peer review anonymous referees. Lack of knowledge about who is acting in the role of referee in structural secrecy therefore leads to trust based on faith in absolute scientific knowledge. Under these structural conditions, any referee judgement would reflect absolute knowledge. The manuscript author and the wider scientific community and beyond would have to have faith in the referee's judgement based on absolute scientific knowledge not on empirical knowledge about who is engaged in the role of judging.

Accordingly, actors in the role of anonymous referee can be constructed as offering objective anonymous knowledge and ignorance in referee judgements, separate

one journal. Other journals in a suite can make use of alternative social forms of peer review. For example, Science, Nature, and The Lancet are flagship journals using traditional peer review within a wider array of journal peer review forms that can include open access to editorial judgements and decisions. 
from the situated knowers that they are (reflecting temporal and spatial situatedness) (see Gaudet, 2014a for referees as situated knowers evaluating scientific explanations). In addition, anonymous dynamics are at odds with precursor social forms of boundary judgement where the roles of inquisitors and censors were non-anonymous (Gaudet 2014b; related in Peters, 1998:chapter one, 59). I advance that supposedly absolute knowledge in turn contributes to the value of scientific 'news' and further naturalizes traditional peer review within and outside of science.

Finally, some scholars have called for the boycott of high prestige commercial journals (i.e., Sample, 2013; Whitfield, 2012) whereas others argue a need to better understand the investments and dynamics of commercial for-profit publishers (Stevenson, $\underline{2013}$ ) and warn to be weary of 'unscrupulous' publishers (2013:268). Scientists have concurrently increasingly question the free labour they provide to for-profit journals (Van Noorden 2013; Verissimo and Roberts, 2013). Given structural secrecy and anonymity, the free labour in the role of referees in traditional peer review cannot yield recognition or credit to potentially compensate for time and expertise invested in the role. Structural properties of secrecy and anonymity can also lead to potential conflicting uses or 'abuse' as becomes apparent when investigating two journal business models in the next subsection: the author-pay and the traditional reader-pay models.

5 - Journal business models: author-pay versus reader-pay

Since Philosophical Transactions, the dominant journal business model has been reader-pay. Contemporary sources of revenue in this model include reader-pay subscriptions or institutional subscriptions via libraries. Other sources of revenue include advertising, author-pay page charges (since 1932, Barschall, 1986:36), reader-pay article access, author-pay fees for colour images and other media, and author-pay manuscript processing fees. Dominant journals typically employ reader-pay business models for their flagship journals. Publishers of dominant journals frequently manage more than one journal where other journals in a suite can make use of alternative social forms of journal peer review. For example, Science has a large array of journals, only one of which is its flagship journal Science that uses traditional peer review.

An alternative business model, author-pay, has arisen with open access journals on the Web (discussed below). Open access generally refers to the free and immediate availability of scientific knowledge and ignorance with minimal restrictions imposed on use (Houghton et al., 2009:XII). In this business model, the journal mainly makes revenue from author payments upon acceptance of their paper for publication following peer review (publication charge). Alternative modes of financing include author-pay submission fees when first submitting a manuscript to a journal (submission charge) (see listing in Mark Ware Consulting, 2010:4) and membership fees (cf., PeerJ journal).

The apparent dependence of open access journals on revenue from author payments, however, has led to charges that journal peer review is not always performed 'rigorously' (Bohannon, 2013). A sponsored 'research' (by the dominant journal Science) that supported such conclusions, for example, submitted a fake and seriously flawed paper to 304 open access journals (Bohannon, 2013). Some 157 journals accepted the fake paper for publication. Furthermore, according to the fake paper researchers, peer review was not always performed or was ill performed. 
I cite this example to analyze two elements. First, the fake 'study' highlights perils of self-regulation in science. These are both at the individual researcher level (who in this case purposefully committed fraud by submitting a fake manuscript and therefore contravened the authors' accountability to empiricism and to the manuscript) and at the journal level (with no oversight over publication and peer review).

Second, I advance that the fake 'study' does not primarily highlight limitations of open access and author-pay models. Rather, it highlights how traditional peer review, with its structural secrecy and anonymity, can potentially be used for conflicting goals or 'exploited' for commercial gain away from scientific and wider public scrutiny.

Traditional peer review is no doubt favoured by potential exploiters or 'unscrupulous' publishers because dominant journals have helped shape it as paradigmatic within and outside of science - giving published peer-reviewed papers a meaning of 'scientific'. It is important to remember, however, that in the seventeenth century the first journal peer review social form emerged under a relation of accountability with the Church (through censorship) and with a learned society where its first editor was trying to earn his living from subscriptions owing to his meager revenue as editor (see Johns, 1998, 2000; Lenafu, 1984:vii). The reader-pay business model at the time was a migration from author-pay scientific exchange where authors since at least the twelfth century paid for (sometimes with the help of sponsors) the scientific exchange of their essays, books, pamphlets, and letters.

Relevant here is that since Philosophical Transactions the reader-pay model seems to have been naturalized in science and that any other type of model could therefore appear 'unnatural', as seems to be the case for author-pay. Furthermore, the apparent abuse of traditional peer review by open access journals contravenes the meaning of peer review as a 'gatekeeper' for good science. Such a contravention could be a contentious issue for dominant journals such as Science that supported the fake study.

More to the point however, and more fundamental than reader-pay versus authorpay business models, structural properties in the social form itself could facilitate abuse and decrease the potential for rational decision-making by editorial readers (Gaudet, 2014b). In extremis, such dynamics resemble those at 'faceless courts' with anonymous judges, sometimes combined with anonymous witnesses. In Columbia, for example, "[w]ith almost no public accountability, the faceless courts seemed to be designed as a cover for corruption" (Knoester, 1998). With this comparison, I do not imply that potential corruption using traditional peer review equates that of Columbia's faceless courts. Like Knoester (1998) and Nagle (1999-2000) who argued that Columbian faceless courts might be exploited by American business interests, however, I do imply that structural secrecy and anonymity that shape relational ties in traditional peer review might be more susceptible to abuse by 'unscrupulous' publishers. Of interest therefore in the shaping of journal peer review is the structural property of anonymity for referees.

\section{Section II - Removing anonymity and instilling double-blind peer review}

Without further historical research, it is difficult to pinpoint where referee anonymity (single-blind peer review) became a widespread cultural practice in journal peer review. Anonymity might have become more widespread from 1832 onward (The Royal Society, 1912:163), though its uptake appears to have been heterogeneous. Single- 
blind peer review, where the name of the referee is not shared with the author (remains anonymous) and the author's name is shared with referees (non-anonymous), has since become a naturalized practice in the paradigmatic form of traditional peer review. This means, therefore, that proposed changes to anonymity are typically compared with the paradigmatic form. In this section, I look at two types of changes (cf., removing anonymity altogether and instilling double-blind peer review), and how these changes help shape journal peer review.

First, I tend to overall dynamics and then analyse three examples. Changes from naturalized traditional peer review anonymity are typically justified in terms of addressing perceived problems in single-blind peer review. Furthermore, journals that offer the option of removing referee anonymity either maintain naturalized closed review where only authors and editorial readers have access to signed editorial judgements, or have created an open review process where signed editorial judgements are openly accessible on the Web (i.e., Pulverer, 2010; van Rooyen et al., 1998; BioMed Central, 2013a; Pöschl, 2010).

Since June 2013, in a first example, Nature Geoscience and Nature Climate Change journals offer an option for double-blind peer review. The option is touted as purportedly removing bias against female authors and other 'unconscious biases' apparently inherent in single-blind peer review (Anonymous, 2013; Nature Publishing Group, 2014). Some of the biases include those "....associated with affiliation, personal reputation, [...] or nationality" (Anonymous, 2014:1). By making the choice of doubleblind optional, however, a purported limitation was that an author who wished to benefit from a bias in affiliation or personal reputation would avoid the double-blind option (Anonymous, 2014:1). However, I advance that more importantly, making double-blind optional reshapes traditional peer review as natural with non-anonymous authors and anonymous referees.

At the open access BioMed Central (owned by Springer since 2008) in a second example, the medical journals and the Biology Direct journal make the referee names non-anonymous and render editorial judgements openly accessible ${ }^{7}$ (Koonin et al., 2006; BioMed Central, 2013a; Koonin et al., 2013). Of interest in this section is how open review is contrasted with traditional peer review's single-blind for referees, and how the paradigmatic form's single-blind is reshaped as natural. This is in spite of pointing to "...the all too obvious pitfalls of anonymous peer review" (Koonin et al., 2013), including "...the uneven duel between omnipotent, anonymous reviewer and helpless author" (Koonin et al., 2006). Furthermore, having briefly elaborated on open peer review BioMed Central reminds readers that "[t]he biology journals within the BMC series operate a traditional, anonymous peer-review process" (my emphasis, BioMed Central, 2013a). Moreover, although celebrating the success of a seven-year 'experiment' of open review at Biology Direct, open review was still framed as filling a 'unique niche' (Koonin et al., 2013:2). Advancing a 'traditional, anonymous peer-review process' and self-marginalizing open review thus help reshape single-blind peer review as natural.

Finally, when then $B M J$ journal editor Richard Smith (1999) advanced that "[m]ost medical journals use the same system [of single-blind peer review], but it's based

\footnotetext{
${ }^{7}$ Medical journals in the BioMed Central series only appear to publish editorial judgements for papers that pass peer review (a dichotomous outcome) whereas the Biology Direct journal publishes all documents for which an author secures the cooperation of three editors.
} 
on custom not evidence" (1999:4), he drew attention to cultural practices in journal peer review. In attempts to resolve the issue of anonymous authors and/or anonymous referees researchers, the $B M J$ and others performed randomised controlled trials (Godlee, 2002:2763). These trials, I advance, constructed peer review as an unproblematic object of study (trials in Smith, 2011:93; van Rooyen et al., 1998; Justice et al., 1998; Godlee, 2002). Some trials failed to 'find any benefit' to double-blind peer review (1999:4). Moreover, although a randomised controlled trial with open peer review did not lead to 'higher quality opinions', Smith (1999) announced that the BMJ was “....introducing open review-for largely ethical reasons" (1999:4). One of the ethical reasons was that "... it seems wrong for somebody making an important judgement on the work of others to do so in secret. A court with an unidentified judge makes us think immediately of totalitarian states" (1999:5). Smith (1999) further advanced that "[o]penness [of review] links accountability with credit" (1999:5; 2011:93) where a referee could be held accountable and receive credit for editorial judgement. Ultimately, he envisaged open review available to all on the Web.

Although Smith $(1999 ; 2011)$ attempted to break free from the custom of singleblind peer review by bringing attention to cultural dynamics, he unwittingly reshaped journal peer review as a rational system of decision-making that can be subject to randomised controlled trials. Such a common sense construction for the object of study is, unfortunately, unlikely to yield well-founded insights (Gaudet, 2014b). Smith's references to legal roots are insightful, however, when framing journal peer review within wider historical dynamics with boundary social forms rooted in legal obligations (Gaudet, 2014b). The potential for change in anonymity and other structural relations in journal peer review are frequently tied with the rise of the Web and its ability to forge and sustain new relations.

\section{Section III - The Web and open access dynamics}

From an initial US defense research electronic network in 1958, came in 1973 an electronic mail and file transfer network, that in the late 1970s was followed by ARPAnet, a precursor to the internet as telephone dial-up with some 2000 users in 1981 (Kern, 2000). The concept of 'virtual journal' encompassing peer review and electronic dissemination of academic papers was first coined in 1978 (Weller, 2000:1328). In keeping with the growth of the Web, low-cost opportunities to publish journals electronically and for scholars to engage in scientific exchange grew. In 1991 for example, “...e-journals were prevalent enough for the Association of Research Libraries (ARL) to publish a Directory of Electronic Journals, Newsletters and Academic Discussion Lists" (2000:1328). Already in 1995 some 115 peer-reviewed e-journals had been identified (2000:1328).

Especially relevant for scientific exchange was ARPAnet's request for comments 'RFC' format of exchange in the 1960-70s whereby scientists could freely post papers and exchange comments (Guédon, 2001:50). Guédon (2001) advanced that Paul Ginsparg might have taken inspiration from RFC to launch the ArXiv preprint server for highenergy physics in 1991. Moreover, in 1994 Stevan Harnad proposed that scholars selfarchive their papers, rendering their content openly accessible (Patton, 2012:27). The Web thus enabled open access to the content of scientific exchange for actors making use 
of electronic infrastructure. Scientific exchange and journal publication on the Web were 'free' from place and temporally-bound paper transmission and control. The type, frequency, and reciprocity of exchange relations actors could engage in mutated.

In attempts to retain control over electronic publishing however, in 1991 commercial journal publishers launched an experimental project (the TULIP project) that would change traditional notions of copyright (Guédon, 2001:39). They launched a licensing system that temporarily licensed scientific documents made available to libraries. From this point forward libraries no longer had ownership of journals, they now licensed journal content for limited temporal periods, for a limited number of users, and under specific conditions of use $\left(\underline{2001: 40)^{8}}\right.$. Open access licensing countered the commercial licensing where open access licenses can yield ownership of content to authors and allow for creative use by the commons (Houghton et al., 2009:119).

As I analyze in this section, the Web helped cultivate at least two dynamics that further shaped journal peer review. First is funding agencies' and education institutions' call for open access to publicly-funded research. Second is the emergence of new social forms of journal peer review, most of which integrated what Donati (2011) referred to as 'creative relationships'.

1 - Open access, self-archiving open access and funding agencies 'knowledge mobilization' strategies

To date, actors involved in shaping journal peer review have come from within journal publishing (cf., referees, editors, publishers). More recently, however, at least one institutional actor external to publication appears to be exercising relations of power over access to the content of journal publications: science public funding agencies.

Here I analyse the increased push by funding agencies and educational institutions, starting at least since 2006 for five of seven Research Councils in the UK, to ensure open access for publicly-funded research papers (i.e., Patton, 2012) and selfarchiving of research papers in institutional repositories (IR) (Gargouri et al., 2010). Funding agencies in Canada, in the United States ${ }^{9}$, and in Europe developed similar policies, eventually requiring open access for publicly-funded research publications within six to twelve months (Scott-Lichter and the Editorial Policy Committee Update, 2012:26-27; Editorial Staff, 2013a). A fundamental rationale driving change was that knowledge from publicly funded research should eventually be accessible free of charge (Harnad, 2011). Educational institutions, for their part, promote IR where authors can deposit preprint or final copies of their published work (Gargouri et al., 2010). In this

\footnotetext{
8 More recently, the 'Lots of Copies Keep Stuff Safe' LOCKSS collaborative digital preservation program seeks to help libraries maintain digital content access in spite of cancelled subscriptions (LOCKSS, 2013).

${ }^{9}$ Since 2008 the US National Institutes of Health (NIH) has a mandatory policy for open access whereby all publicly-funded health papers must be open access at most twelve months after their initial publication (embargo period) (Vollmer, 2014; UIC, 2014). In 2006 there was a more general proposal to render all science publications open access that did not pass the House or the Senate. A recent version of the act, the Frontiers in Innovation, Research, Science and Technology Act (FIRST Act) has also, as yet, not passed the House or the Senate (GovTrack.us:2014). A contentious element in the 2014 version is that it extends the embargo period to three years for publishers who can continue to charge readers during that period (Vollmer, 2014).
} 
way, funding agencies and educational institutions are promoting open access knowledge mobilization with no financial barriers to potential uptake within and beyond academia.

On the one hand, funding agencies and educational institutions are diminishing long-term revenue potential for commercial journal publishers for publicly funded research, also peer-reviewed for free by academics. On the other hand, given that funding agencies and educational institutions appear driven by a focus on knowledge (Gaudet, 2013), they are privileging the naturalized dichotomous outcome of traditional peer review and a naturalized measure of academic success - a published paper. Funding agencies and educational institutions therefore bypass a rich potential of scientific exchange with knowledge and ignorance in journal peer review: the original manuscript and editorial judgements and decisions. By extension, they also help shape traditional peer review as paradigmatic.

As they stand, mandated open access dynamics therefore appear to sustain traditional peer review and its structural secrecy. More fundamentally, however, mandated open access dynamics reveal the relations of power that funding agencies can potentially hold over access to the content of peer reviewed scientific exchange. In efforts to maximize publicly funded research funding investments, and I advance increase knowledge and ignorance production (Gaudet, 2014a), some funders have gone as far as helping establish a new journal with collaborative, open peer review. I analyse such an example in the next sub-section.

2 - 'Creative relationships' in alternative contemporary social forms of boundary judgement - the emergence of new social forms

In the final sub-section, I explore how the Web and the push for greater open access by academics (and funders) has led to the emergence of new contemporary social forms of boundary judgement. In the early 1990s, two actors leading the movement away from commercial publishers and their subscription models were ArXiv founder Paul Ginsparg and Canadian academic Stevan Harnad (Guédon, 2003:184). Some of the new social forms include what Donati (2011) refers to as 'creative relationships' (2011:220). By creative relationships I refer to relations that cannot be captured by action theories centered on an individual rational actor approach or a uniquely structural theoretical approach that abstracts individual actor motivation and meaning. As developed above, the theoretical context developed here is relational - a social form approach - and thus sensitive to capturing and focusing on the emergence and dissolution of creative relations. At the heart of the new relations is open access.

One of the earlier open access journals that led to the emergence of a new social form of boundary judgement is the Public Library of Science (PLoS) science and medicine journal PLoS ONE. Before the launch of its suite of open access journals, however, at the end of the 1990s the PLoS had amassed over 30,000 names that supported an alternative to the dominant subscription-based commercial publisher model of academic publishing (Guédon, 2003:184). In addition, given funding for the PLoS was ensured by a grant from the Moore Foundation, a not-for-profit economic actor bolstered PLoS.

The journal peer review social form at the PLOS ONE journal discussed in Gaudet (2014a) involves the removal of a criterion for originality - lite traditional peer review. 
The journal therefore only assesses scientific soundness of papers. The Web-based journal includes a forum for continued scientific exchange on articles published. The long-term potential for continued peer review is an example of a creative relation rendered easier with the Web (as opposed to letters to the editor that be inaccessible).

Moreover, I advance that removing the criterion for originality appears to remove the 'news' value associated with a peer reviewed paper. It thus solely retains its epistemic value - valuable knowledge and ignorance. The PLoS suite of journals has not done away with valuing originality, however, and constructs its PLoS Biology and PLoS Medicine journals as flagship journals inviting original and influential papers with an acceptance rate below $10 \%$ of submissions (PLOS ONE, 2013). PLOS ONE is thus an exception in the PLoS suite of on-line journals that once more shapes the 'naturalness' of traditional peer review when set against its flagship journals.

With the growth of the Web, the increase in open access papers has flourished and one estimate reported that the tipping point of over $50 \%$ of papers free of access had been reached from 2004 to 2011 in several countries (Archambault et al., 2013). One example of a new journal designed to contribute to open access dynamics, eLife, was a joint initiative that included three research funders: the Howard Hughes Medical Institute, the Max Planck Society, and the Wellcome Trust. The social form of boundary judgement they constructed for eLife removed structural secrecy among referees (cf., exchange among referees is encouraged), removed structural secrecy for editorial judgements (upon approval by authors), and invited post-publication exchange with readers (eLife, 2013). A direct active role by funding agencies in journal publication in this example helped shape journal peer review away from producing 'news' as a commodity with market value to producing 'knowledge and ignorance' as a commodity with scientific value.

Another example of new creative relations is the form of public space peer review. Public space peer review is used at some open access journals (i.e., Atmospheric Chemistry and Physics as one of the suite of journals at Copernicus Publications, Pöschl, 2012; BioMed Central, Biology Direct (Koonin et al., 2013; BioMed Central, 2013a). Open review in this case refers to the permanent open access to referee judgements (anonymous or non-anonymous) and to editorial comments and judgements.

The Copernicus model is used here to briefly present the social form of public space peer review. In pre-publication the editor enters into relation with a manuscript in a pre-screening 'access review' (to confirm alignment of the manuscript with the journal scope and to identify and correct potential technical errors). The form then becomes fully 'open'. The original manuscript (a.k.a., the discussion paper at Copernicus journals) is visible and therefore the author holds an explicit relation of accountability to it. Referees (anonymous or non-anonymous) are held to account to visible editorial judgements and editors are held to account to visible decisions. Scholars and non-scholars can relate with the discussion paper and all other comments, judgements, and decisions through short comments. The author can relate with these through comments as well. Even if the final editorial decision is to reject a manuscript for publication, the outcome is therefore not dichotomous and does not contribute to ignorance reproduction. If a paper is 'published', the author's final paper relates with the discussion paper and all comments, judgements, and decisions. Finally, as with traditional peer review, actors can hold additional potential political and economic relations (cf., to funders, to journal owners/publishers, advertisers) as well as a relation of accountability to empiricism (Gaudet, 2014a, 2014b). 
The Atmospheric Chemistry and Physics journal was launched in 2001. The European Geosciences Union and the open access publisher Copernicus Publications run the journal (among others). What I wish to draw attention to in the social form is the enhanced condition of possibility for scientific exchange that the intersection of open access and public space peer review has created - increasing potential for creative relationships. The transparency under which relations are engaged in - and whose traces (in judgements and decisions) are maintained visibly on the Web - maximize the potential for ignorance production. The scientific value (or not) constructed through public space peer review thus retains potentiality for ignorance production in perpetuity.

Understood through Guédon's (2003) analysis of the commercial publisher-led publication system, eLife and public space peer review support that "...the [Web-based] technology [is] transparent enough to reveal all sorts of possibilities that [can] obviously subvert many instituted social and institutional relations" (2003:184). eLife and Public space peer review do indeed challenge what some commercial power relations have established as seemingly 'naturalized' relations for peer review.

Finally, transparent open access scientific exchange on preprint servers such as ArXiv has increased the potential for valuation of scientific exchange outside of peer review, reminiscent of the valuation of scientific exchange from the twelfth century to the rise of the printing press. For physicists, bioinformaticians, and mathematicians scientific exchange through a preprint archive (cf., ArXiv, Nature Precedings) has come to impart value to the content of exchange. For example, posting a paper on such a server can secure priority claims for researchers in these disciplines (i.e., Seppänen et al., 2012).

Beyond the dynamics that I have analyzed here, the Web and its potential for 'creative relationships' continues to shape journal peer review and scientific exchange. I conclude with a summary and three implications.

\section{Conclusion}

The main goal for the paper was to analyse the shaping of contemporary journal peer review. It would appear that commercial journal publishers mostly gained interest in the market once the SCI helped establish 'core journals' and publishers could dominate an inelastic market. Traditional peer review, with secrecy and referee anonymity is especially well suited to construct news with market value. Moreover, the advent of the Web has helped academics and funding agencies become dominant actors that can reshape journal peer review with creative relationships. These include being free from place and temporally-bound paper transmission and control, removing anonymity, removing structural secrecy, increasing scientific exchange outside boundary judgement social forms, and long-term potential for new or evolving relations. Overall, the type, frequency, and reciprocity of exchange relations actors could engage in, mutated. The Web has also enabled increased open access dynamics and self-archiving that increased scientific exchange but conflicts with the traditional reader-pay business model. Finally, the content of scientific exchange on preprint servers such as ArXiv appears to increasingly hold value in disciplines that make use of such servers.

The paper holds at least three implications. First is that analysis of journal peer review and journal publishing more generally must consider shifting to scientific analysis of the objects of study (Gaudet, 2014b) rather than common experience (i.e., author-pay 
vs. reader-pay). It is my contention that constructing journal peer review as social form can help steer analysis to structural properties underlying complex dynamics. It is also my contention that scientific analysis can steer analysis away from profitability discourse towards social form and scientific exchange discourse. Profitable publishing does not preclude increased scientific exchange as is evident at Copernicus (Pöschl, 2010, 2012) and BioMed Central bought out by publisher Springer in 2008 (BioMed Central, 2013b).

Second is that shaping of journal peer review cannot be understood without due consideration for economic dynamics. That publishers could hold relations of power over scientific evaluation systems for career management merits continued scrutiny. It would seem that branding of journals and of individual scientists who publish in them intersects with scientific exchange of publicly paid research. Furthermore, on the one hand structural secrecy for original manuscript and editorial judgements and decisions can be used to (1) bolster news value for scientific knowledge and ignorance and (2) allow supposedly 'unscrupulous' journals to publish papers that can be perceived as not meeting the norms of boundary for what is deemed as scientific, or not. On the other hand, creative relationships made possible with the Web can alter the economics of publishing (cf., open access publishers with academic editorial boards such as Copernicus have self-sustaining business models) and transparency in journal peer review (with increased open scientific exchange without the contingency of peer review).

Finally I explore implications of anonymity. That a referee could ever be made anonymous is a significant point of departure from early editorial judgement social forms of inquisition and censorship that also created boundaries between what was deemed scientific, or not (Gaudet, 2014b). In these forms, actors engaged in the role of making judgements were not anonymous in keeping with Roman Law as established legal procedure (Peters, 1988: chapter one, 59). Still today, judges are only very rarely anonymous or 'faceless' because transparency is an underlying legal principle that requires a judge to be named and requires decision-making "...open to the scrutiny of the public" (Waddams, 1992:9; see examples of faceless courts above). The spotlight Smith (1999; 2011) shone on ethical issues of anonymous referees and related calls for referee accountability and credit can therefore be understood within a wider historical framework of legal obligations in boundary judgement social forms. This corresponds to a shift from journal publishing with legal oversight under the censorship function of inquisition to self-regulation in science (Gaudet, 2014b; related in Biagioli, 2002).

To conclude, all that apparently glitters in traditional peer review, it would seem, is not gold at natural scientific and medical journals. Investigating the shaping of journal peer review, the reshaping of traditional peer review as paradigmatic, and the intersection of boundary judgement forms with economic dynamics help further understanding on calls for transparency in self-regulated academic publishing.

\section{Acknowledgements}

I thank my doctoral supervisor for comments on a related earlier draft and committee members and academics with whom I exchanged on the topic. Please note that the ideas, arguments, and remaining errors in this work are solely mine and do not necessarily reflect the views of the individuals above. Research was supported in part by a JosephArmand Bombardier Canada Graduate Scholarship from the Social Sciences and Humanities Research Council of Canada. 


\section{References}

Altman, L.K. 1996. "The Ingelfinger rule, embargoes, and journal peer review-part 1."

The Lancet 347:1382-1386.

American Mathematical Society (AMS). 2011, "Journal Price Survey (1994-2011)",

Retrieved December 4, 2013 (http://www.ams.org/membership/journal-

survey.html).

Anonymous. 2013. "Double-blind peer review." Nature Geoscience 6:413.

—. 2014. "Editorial: Peer-review variations." Nature Geoscience 7:1.

Archambault, É., D. Amyot, P. Deschamps, A. Nicol, L. Rebout, and G. Roberge. 2013.

"Proportion of Open Access Peer-Reviewed Papers at the European and World

Levels - 2004-2011.” Montreal QC: European Commission DG Research \& Innovation.

Barschall, H.H. 1986. "The Cost of Physics Journals.” Physics Today 39:34-36.

Bazerman, C. 1988. Shaping Written Knowledge: The Genre and Activity of the

Experimental Article in Science. Madison WI: The University of Wisconsin Press.

Bergstrom, C.T. and T.C. Bergstrom. 2006. "The economics of ecology journals."

Frontiers in Ecology 4:488-495.

Bergstrom, T.C. 2001. "Free Labor for Costly Journals?" Journal of Economic

Perspectives 15:183-198.

Biagioli, M. 2002. "From Book Censorship to Academic Peer Review." Emergences:

Journal for the Study of Media \& Composite Cultures 12:11-45.

BioMed Central. 2013a. "What is 'open peer review', as operated by the medical journals

in the BMC series?" Retrieved 2 September, 2013

(http://www.biomedcentral.com/authors/authorfaq/medical).

—. 2013b, Springer acquisition FAQ. Accessed December 2, 2013.

http://www.biomedcentral.com/libraries/springerfaq.

Bohannon, J. 2013. "Who's Afraid of Peer Review?" Science 432:60-65.

Bornmann,L., M. Ruediger, and D. Hans-Dieter. 2010. "A Reliability-Generalization

Study of Journal Peer Reviews: A Multilevel Meta-Analysis of Inter-Rater

Reliability and Its Determinants." PLoS ONE 5:e14331.

Bourdieu, P., J.-C. Passeron, and J.-C. Chamboredon. 1968. Le métier de sociologue:

Livre I. Paris: École Pratique des Hautes Études, Mouton and Bordas.

Bryce, A., J. Qin, and F.W. Lancaster. 1994. "Persuasive Communities: A Longitudinal Analysis of References in the Philosophical Transactions of the Royal Society, 1665-1990." Social Studies of Science 24: 279-231.

Burnham, J.C. 1990. "The Evolution of Editorial Peer Review." Journal of the American Medical Association 263:1323-1329.

Cambridge Economic Policy Associates. 2008. "Activities, costs and funding flows in the scholarly communications system in the UK: Full Report." Report commissioned by the Research Information Network (RIN), May 2008.

CBC. 2013. Bogus science paper reveals peer review's flaws: John Bohannon found that many journals are not living up to their peer review promises. CBC News.

Technology \& Science. Retrieved December 12, 2013. http://www.cbc.ca/news/technology/bogus-science-paper-reveals-peer-review-sflaws-1.2054004 
Donati, P. 2011. Relational Sociology: A new paradigm for the social sciences. New York: Routledge.

Durkheim, É. [1894]1988. Les règles de la méthode sociologique. Saint-Amand: Flammarion.

Editorial Staff. 2012. Scientific Publishing: The Price of Information. The Economist, 13. Accessed Oct. 19, 2012. http://www.economist.com/node/21545974.

—. 2013a. "Free-for-all." The Economist, 9. Accessed May 10, 2013. http://www.economist.com/news/science-and-technology/21577035-open-accessscientific-publishing-gaining-ground-free-all.

—. 2013b. "Unreliable research: trouble at the lab." The Economist, 1-10. Accessed Oct. 22, 2013. http://www.economist.com/news/briefing/21588057-scientists-thinkscience-self-correcting-alarming-degree-it-not-trouble.

eLife. 2013, "Review Process eLife", Retrieved 5 August, 2013

(http://www.elifesciences.org/the-journal/review-process/).

Flyvberg, B. 2001. Making Social Science Matter: Why social inquiry fails and how it can succeed again. Cambridge: Cambridge University Press.

-. 2006. "Five Misunderstandings About Case-Study Research." Qualitative Inquiry. 12:219-245.

Garfield, E. 1970. “Citation Indexing for Studying Science.” Nature 227:669-671.

—. 1998. "Decade-Long Legal Battle Focused on Journal Cost, Impact." The Scientist, (http://www.the-scientist.com/?articles.view/articleNo/18779/title/Decade-LongLegal-Battle-Focused-On-Journal-Cost--Impact/).

Garfield, E. and I.H. Sher. 1963. "New Factors in the Evaluation of Scientific Literature, Through Citation Indexing." American Documentation 14:195-201.

Gargouri, Y., C. Hajjem, V. Larivière, Y. Gingras, L. Carr, T. Brody, and S. Harnad. 2010. "Self-Selected or Mandated, Open Access Increases Citation Impact for Higher Quality Research." PLoS ONE 5:e13636.

Gaudet, J. 2013. "It takes two to tango: knowledge mobilization and ignorance mobilization in science research." Prometheus: Critical Studies in Innovation 31:169-187. http://www.tandfonline.com/doi/full/10.1080/08109028.2013.847604

—. 2014a. How pre-publication journal peer review (re)produces ignorance at scientific and medical journals: a case study. uO Research. Pp. 1-67. http://hdl.handle.net/10393/31198

—. 2014b. Investigating journal peer review as scientific object of study. uO Research. 111. http://hdl.handle.net/10393/31161

Godlee, F. 2002. "Making Reviewers Visible: Openness, Accountability, and Credit." Journal of the American Medical Association 287:27-62-2765.

Gross, A.G. and J.E. Harmon. 2014. Science from Sight to Insight: How Scientists Illustrate Meaning. Chicago: The University of Chicago Press.

Gould, T.H.P. 2012. "The Church and Peer Review: Was 'Peer' Review Fairer, More Honest Then Than Now?" Journal of Scholarly Publishing 36:60.

—. 2013. Do We Still Need Peer Review? Toronto: The Scarecrow Press, Inc.

GovTrack.us. 2014. H.R. 4186: FIRST Act of 2014. Civic Impulse, LLC. Accessed June 26, 2014. https://www.govtrack.us/congress/bills/113/hr4186. 
Guédon, J.-C. 2001. "In Oldenburg's Long Shadow: Librarians, Research Scientists, Publishers, and the Control of Scientific Publishing." Pp. 1-69. Washington, D.C.: Association of Research Libraries.

—. 2003. "Locating the Information Society within Civil Society: The Case of Scientific and Scholarly Publications." Pp. 165-194 in Communicating in the Information Society, edited by B. Girard and S. Ó. Siochrú. Geneva: United Nations Research Institute for Social Development (UNRISD).

Harnad, S. 2011. "Open Access to Research: Changing Researcher Behaviour Through University and Funder Mandates." eJournal of eDemocracy (JeDEM) 3:33-41.

Hirschauer, S. 2010. "Editorial Judgments: A Praxeology of "Voting' in Peer Review." Social Studies of Science 40:71-103.

Houghton, J., B. Rasmussen, P. Sheehan, C. Oppenheim, A. Morris, C. Creaser, H. Greenwood, M. Summers, and A. Gourlay. 2009. "Economic implications of alternative scholarly publishing models: Exploring the costs and benefits. A report to the Joint Information Systems Committee." Victoria University and Loughborough University.

Ingelfinger, F.J. 1974. "Peer Review in Biomedical Publication." The American Journal of Medicine 56:686-692.

Ioannidis, J.P.A., L. Manzoli, C. De Vito, M. D’Addario and P. Villari. 2011. "Publication Delay of Randomized Trials on 2009 Influenza A (H1N1) Vaccination." PLoS ONE. 6:e28346.

Jasanoff, S. 1990. The Fifth Branch: Science Advisers as Policymakers. Cambridge MA: Harvard University Press.

Johns, A. 1998. The Nature of the Book: Print and Knowledge in the Making. Chicago: The University of Chicago Press.

Justice, A.C., M.K. Cho, M.A. Winker, J.A. Berlin, and D. Rennie. 1998. "Does Masking Author Identity Improve Peer Review Quality?" JAMA 280:240-242.

Kennefick, D. 2005. "Einstein versus the Physical Review: A great scientist can benefit from peer review, even while refusing to have anything to do with it." Physics Today, September: pp. 43-48.

Kern, S. 2000. "Time and Medicine.” Annals of Internal Medicine 132:1-9.

Knoester, M. 1998. "War in Colombia." Social Justice 25:85+.

Koonin, E.V., L.F. Landweber, and D.J. Lipman. 2013. "Biology direct: celebrating 7 years of open, published peer review." Biology Direct 8.

Koonin, E.V., L.F. Landweber, D.J. Lipman, and R. Dignon. 2006. "Reviving a culture of scientific debate." Nature. doi:10.1038/nature05005.

Laplante, J. 2014. "On Knowing and Not Knowing "Life" in Molecular Biology and Xhosa Healing: Ontologies in the Preclinical Trials of a South African Indigenous Medicine (Muthi)." Anthropology of Consciousness. 25:1-31.

Latour, B. and S. Woolgar. 1986. Laboratory Life: The Construction of Scientific Facts. Princeton: Princeton University Press.

Lefanu, W.R. 1984. British Periodicals of Medicine 1640-1899. Oxford: Welcome Unit for the History of Medicine.

Levine, D.N. (Ed.). 1971. Georg Simmel: On Individuality and Social Forms, Selected Writings. Chicago: The University of Chicago Press.

Lips, H.M. 1991. Women, Men, and Power. Toronto: Mayfield Publishing Company. 
LOCKSS. 2013, "Lots of Copies Keep Stuff Safe", Retrieved 13 June, 2013 (http://www.loskss.org).

Lopez, J. 2004. "How Sociology can Save Bioethics... Maybe." Sociology of Health \& Illness 26:875-896.

—. 2009. "Par-delà l'éthique : vers une sociologie des pratiques éthiques contemporaines." Cahiers de Recherche Sociologique 48:27-44.

Macdonald, Stuart. 2013. Editorial. Prometheus: Critical Studies in Innovation. 31: 167168.

Mark Ware Consulting. 2010. "Submission Fees - A tool in the transition to open access? Summary of report to Knowledge Exchange." Bristol UK: Mark Ware Consulting Ltd: Publishing and Elearning Consultancy.

McClellan, J.E.I. 1985. Science Reorganized: Scientific Societies in The Eighteenth Century. New York: Columbia University Press.

Musselin, C. 2013. "How peer review empowers the academic profession and university managers: Changes in relationships between the state, universities and the professoriate." Research Policy.

Nagle, L.E. 1999-2000. "Columbia's faceless justice: A necessary evil, blind impartiality or modern inquisition?" University of Pittsburgh Law Review 61:881-954.

Nature Publishing Group. 2014, "Peer Review Policy”, Retrieved 1 December, 2013 (http://www.nature.com/authors/policies/peer_review.html).

Parrott, J. 2004, "Scholarly Societies and their Relationships with Commercial Publishers", Retrieved October 20, 2013 (http://www.lib.uwaterloo.ca/society/comm_publishers.html).

Patton, M.D. 2012. "The Rhetorical Ecology of Peer Review: Changes in the Digital Age."'RECV: Engaging Cultures and Voices:1-28.

Peters, E. 1988. Inquisition. New York: The Free Press.

PLoS ONE. 2013, “Journals”, Retrieved 25 June, 2013 (http://www.plos.org/publications/journals/).

Pöschl, U. 2010. "Interactive open access publishing and public peer review: The effectiveness of transparency and self-regulation in scientific quality assurance." International Federation of Library Associations and Institutions 36:40-46.

—. 2012. "Multi-stage open peer review: scientific evaluation integrating the strengths of traditional peer review with the virtues of transparency and self-regulation."

Frontiers in Computational Neuroscience. 6:1-16.

Pulverer, B. 2010. "Transparency showcases strength of peer review." Nature 468:29-31.

Sample, I. 2013, "Nobel winner declares boycott of top science journals: Randy Schekman says his lab will no longer send papers to Nature, Cell and Science as they distort scientific process." The Guardian. December 92013.

Scott-Lichter, D. and the Editorial Policy Committee. 2012 Update. "CSE's White Paper on Promoting Integrity in Scientific Journal Publications." Wheat Ridge, CO: Council of Science Editors (CSE).

Sense About Science. 2012. "Peer Review: the Nuts and Bolts." London: Sense About Science.

Sent, E.-M. and A. Klamer. 2002. "The economics of scientific publication: Introduction.” Journal of Economic Methodology 9:265-273. 
Seppänen, J.-T., M. Mönkkönen, and J.S. Kotiaho. 2012. "Peer review by the Peers, for the Peers: response to Hettyey et al." Trends in Ecology and Evolution 27:191-192.

Smith, R. 1999. "Opening up BMJ peer review: A beginning that should lead to complete transparency." BMJ 318:4-5.

—. 2006. "Peer review: a flawed process at the heart of science and journals." Journal of the Royal Society of Medicine 99:178-182.

—. 2011. The Trouble with Medical Journals. London: The Royal Society of Medicine Press Limited.

Stanford University. 1997, "Gordon and Breach Science v. American Institute of Physics and American Physical Society", Retrieved 20 November, 2013 (http://barschall.stanford.edu/).

Stevenson, I. 2013. "Academic publishing riposte. Do not shoot the messenger." Prometheus: Critical Studies in Innovation, 31:3, 265-268. http://dx.doi.org/10.1080/08109028.2014.891713

The Royal Society. 1912. The Record of the Royal Society of London. London: Oxford University Press.

UIC (University of Illinois at Chicago). 2014. OA Legislation - Publishing, Scholarly Communication, and Open Access - Research and Subject Guides at University of Illinois at Chicago. Accessed June 26, 2014. http://researchguides.uic.edu/oapolicies.

Van Noorden , R. 2013. "The True Cost of Science Publishing: Cheap open-access journals raise questions about the value publishers add for their money " Nature 495:426-429.

van Rooyen, S., F. Godlee, S. Evans, and R. Smith. 1998. "Effect of Blinding and Unmasking on the Quality of Peer Review: A Randomized Trial.” Journal of the American Medical Association 280:234-237.

Verissimo, D. and D.L. Roberts. 2013. "The academic welfare state: making peer-review count." Trends in Ecology \& Evolution 28:623-624.

Vollmer, T. 2014. Public access: First Act moving ahead in US Congress. Accessed June 26, 2014. http://creativecommons.org/weblog/entry/42765.

Waddams, S.M. 1992. Introduction to the study of law. Fourth Edition. Scarborough: Carswell.

Weller, A.C. 2000. "Editorial Peer Review for Electronic Journals: Current Issues and Emerging Models." Journal of the American Society for Information Science 51:328-1333.

Whitfield, J. 2012. "Elsevier boycott gathers pace: Rebel academics ponder how to break free of commercial publishers." Nature News. Accessed October 25, 2012. http://www.nature.com/news/elsevier-boycott-gathers-pace-1.10010

Young, N.S., J.P.A. Ioannidis, and O. Al-Ubaydli. 2008. "Why Current Publication Practices May Distort Science.” PLoS Med 5:e201. http://www.plosmedicine.org/article/info:doi/10.1371/journal.pmed.0050201.

Zavarzadeh, M.U. and D. Morton. 1991. Theory, (Post)Modernity, Opposition: An "Other" Introduction to Literary and Cultural Theory. Washington: Maissonneuve Press.

Zuckerman, H. and R.K. Merton. 1971. "Patterns of evaluation in science: institutionalization, Structure and Functions of the referee system." Minerva 9:66100 . 